\title{
Polymorphism in the EREG gene confers susceptibility to tuberculosis
}

Wen Cao ${ }^{1+}$, Liu-lin Luo ${ }^{1+}$, Wei-wei Chen ${ }^{1}$, Li Liang ${ }^{1}$, Ran-ran Zhang ${ }^{1}$, Yan-lin Zhao ${ }^{2}$, Jin Chen ${ }^{1 *}$ and Jun Yue (1) $^{*}$

\begin{abstract}
Background: Host genetic factors affect the immune response to Mycobacterium tuberculosis (Mtb) infection as well as the progression of the disease. Epiregulin (EREG) belongs to the epidermal growth factor (EGF) family, which binds to the epidermal growth factor receptor (EGFR) to regulate the immune response of the host during infections. Our study aimed to compare EREG levels in tuberculosis (TB) patients and healthy controls and assess whether polymorphisms in EREG increase the risk of TB.

Methods: We used ELISA to determine the plasma EREG level from 30 healthy controls and 50 tuberculosis patients. By evaluating the EREG gene from 624 TB patients and 600 healthy controls, we determined the allelic and genotypic frequencies for association with susceptibility to TB infections in this group.

Results: This paper shows that the pulmonary tuberculosis (PTB) and extrapulmonary tuberculosis (EPTB) groups showed a significantly higher plasma EREG level $(1014 \pm 733.9 \mathrm{pg} / \mathrm{ml}, 700.2 \pm 676.6 \mathrm{pg} / \mathrm{ml}$, respectively) than the healthy controls $(277 \pm 105.4 \mathrm{pg} / \mathrm{ml})$. The rs 2367707 polymorphism was associated with a higher risk of PTB and EPTB $(P=0.00051, P=0.0012)$. Analyses of haplotype frequencies found that people with the haplotype CACAT had a higher risk of PTB and EPTB ( $P=0.00031, \mathrm{OR}=1.43 ; P=0.000053, \mathrm{OR}=1.65)$. Moreover, the rs6446993

polymorphism of the EREG gene was found to be associated with EPTB $(P=0.00087, \mathrm{OR}=1.54 ; 95 \% \mathrm{Cl}=1.23-1.94)$.

Conclusions: Compared to that of healthy controls, the level of EREG in the plasma of TB patients increased significantly. Based on these data, we demonstrated that EREG polymorphisms are genetic factors for susceptibility to TB and various forms of TB.
\end{abstract}

Keywords: Tuberculosis, Epiregulin, Single nucleotide polymorphism, Susceptibility

\section{Background}

Tuberculosis (TB) is an infectious disease caused by Mycobacterium tuberculosis (Mtb) and has been a leading cause of human mortality worldwide over many decades, with an estimated global burden of 1.4 million TB deaths and 10.4 million new TB cases in 2017 [1]. Macrophages play a crucial role in the immune system by ingesting and degrading invading $M t b$; they are a link between the inflammatory response and the adaptive immune response [2]. Host genetic factors affect the immune response to $M t b$ infection and the occurrence and development of TB. Candidate gene and genome-wide

\footnotetext{
* Correspondence: chenjindor@aliyun.com; yuejunnan@aliyun.com

'Wen Cao and Liu-lin Luo contributed equally to this work.

'Shanghai Key Laboratory of Mycobacterium Tuberculosis, Shanghai Pulmonary Hospital Affiliated to Tongji University School of Medicine, Shanghai, People's Republic of China

Full list of author information is available at the end of the article
}

association (GWAS) research has studied the relationship between the human genetic background and susceptibility to TB, but the mechanism is unknown $[3,4]$. Describing the interplay between host genetics and $M t b$ may provide insight into the occurrence, progression and control of the disease.

Epiregulin (EREG) belongs to the epidermal growth factor (EGF) family, whose members bind to the epidermal growth factor receptor (EGFR) or ErbB4 to generate signals for proliferation, migration, differentiation, cytokine secretion and innate immunity [5]. Compared with the expression in PTB and LTB patients, the expression of EREG in macrophages from patients with TBM increased [6]. Macrophages express EREG to modulate the host immune response to TLR ligands. The expression of EREG in the lungs of mice infected with $M t b$ was also significantly increased [7]. Recent data have suggested

(c) The Author(s). 2019 Open Access This article is distributed under the terms of the Creative Commons Attribution 4.0 International License (http://creativecommons.org/licenses/by/4.0/), which permits unrestricted use, distribution, and reproduction in any medium, provided you give appropriate credit to the original author(s) and the source, provide a link to the Creative Commons license, and indicate if changes were made. The Creative Commons Public Domain Dedication waiver (http://creativecommons.org/publicdomain/zero/1.0/) applies to the data made available in this article, unless otherwise stated. 
that EREG expression is also induced in monocytes after stimulating with $M t b$ and TLR4 and TLR2/1/6 ligands. In murine macrophages, EREG expression induced by $M t b$ is TLR2- and MYD88- dependent. Taken together, these studies demonstrate that EREG plays a functional role in TB pathogenesis and innate immunity [8]. EREG exists in two forms: a membrane-bound form and mature secreted form. The membrane-bound form regulates cytokine production in macrophage [9]. Compared to the cytokine levels of wild-type mice, IL- 6 and TNF- $\alpha$ levels were lower in peritoneal macrophages (PM) from EREG knockout mice stimulated with lipopolysaccharides (LPS) and peptidoglycan (PGN). By downregulating IL-18, soluble EREG played a role in modulating the inflammatory pathway [10]. These data suggest that EREG is crucial for the control of $M t b$ infection. Therefore, we hypothesized that polymorphisms of the EREG gene may influence $M t b$ infection in humans.

In this paper, our goal was to determine EREG gene SNPs and the level of EREG in the plasma of TB patients compared to healthy controls.

\section{Materials and methods \\ Subjects}

In this case-control study, 1224 subjects were recruited: 600 healthy controls (HC), 424 pulmonary TB patients (PTB) and 200 extra-pulmonary TB patients (EPTB). All volunteers were enlisted from the Shanghai Pulmonary Hospital. Members of the control population were $>18$ years of age and attested to no history of TB; their PPD tests and QFT tests were negative, and no evidence of prior $\mathrm{TB}$ presented in the chest radiographies. There were 340 males and 260 females, and the mean age was $34.66 \pm 9.70$. Mtb infections were confirmed in the TB patients included according to evidence of positive sputum smears and cultures, as well as clinical and radiography features. In the PTB groups, there were 250 males and 174 females, and the mean age was $35.44 \pm 13.65$. In the EPTB groups, there were 121 males and 79 females, and the mean age was $35.63 \pm 17.22$; there were 13 patients with intestinal tuberculosis, 10 patients with bone tuberculosis, 16 patients with lymph node tuberculosis, 60 patients with meningeal tuberculosis, 26 patients with genital tuberculosis, 64 patients with pleurisy tuberculosis, and 11 patients with renal tuberculosis, as shown in Table 1.

\section{Ethics statement}

All subjects volunteered for the study and signed informed consent forms. In addition, the Ethics Committee of Shanghai Pulmonary Hospital affiliated with Tongji University School of Medicine approved the study.
Table 1 Clinical characteristics of individuals stratified according to differences in infection locations

\begin{tabular}{|c|c|c|c|c|c|c|}
\hline Subgroup & Number & Male & Female & $P$ & Age $^{c}$ & $P^{*}$ \\
\hline Control & 600 & $340(56.7 \%)$ & $260(43.3 \%)$ & & $\begin{array}{l}34.66 \pm \\
9.70\end{array}$ & \\
\hline PTB $^{a}$ & 424 & $250(59.0 \%)$ & $174(41.0 \%)$ & $0.46^{\mathrm{a}}$ & $\begin{array}{l}35.44 \\
\pm 13.65\end{array}$ & $0.26^{a}$ \\
\hline EPTB $^{b}$ & 200 & $121(60.5 \%)$ & 79 (39.5\%) & $0.34^{b}$ & $\begin{array}{l}35.63 \\
\pm 17.22\end{array}$ & $0.33^{b}$ \\
\hline $\begin{array}{l}\text { Intestine } \\
\text { TB }\end{array}$ & 13 & 6 & 7 & & $\begin{array}{l}40.85 \\
\pm 18.87\end{array}$ & \\
\hline Bone TB & 10 & 4 & 6 & & $\begin{array}{l}36.30 \\
\pm 10.37\end{array}$ & \\
\hline LNTB & 16 & 4 & 12 & & $\begin{array}{l}44.25 \\
\pm 15.64\end{array}$ & \\
\hline $\begin{array}{l}\text { TB } \\
\text { Meningitis }\end{array}$ & 60 & 40 & 20 & & $\begin{array}{l}33.68 \\
\pm 18.04\end{array}$ & \\
\hline Genital TB & 26 & 18 & 8 & & $\begin{array}{l}41.19 \\
\pm 14.18\end{array}$ & \\
\hline $\begin{array}{l}\text { Pleurisy } \\
\text { TB }\end{array}$ & 64 & 42 & 22 & & $\begin{array}{l}31.81 \\
\pm 16.39\end{array}$ & \\
\hline Renal TB & 11 & 7 & 4 & & $\begin{array}{l}35.91 \\
\pm 23.23\end{array}$ & \\
\hline
\end{tabular}

a PTB pulmonary tuberculosis patients

${ }^{\mathrm{b}}$ EPTB extra-pulmonary tuberculosis patients

${ }^{c}$ Age (years) $=$ Mean \pm SD

$p$-value calculated by $x^{2}$ test for gender between TB patients and Controls

${ }^{*} P$-value calculated by $t$-test for age between TB patients and Controls

\section{Determination of plasma EREG levels}

Thirty healthy controls and $50 \mathrm{~TB}$ patients, who were not selected from the genotyped individuals, were picked randomly to have their plasma separated from $200 \mu \mathrm{l}$ EDTA anticoagulated blood by centrifugation. Following the manufacturer's protocol, ELISA kits (R\&D systems, MN, USA) were used for detecting EREG levels.

\section{Selection of DNA variants for EREG genotyping}

We selected 5 SNPs from EREG (rs10518126, rs2367707, rs3806794, rs6446993, rs6836436), and the tag SNPs were chosen from the 1000 Genomes Project Phage3. The general rule for selecting tagged SNPs were an $R^{2}$ linkage disequilibrium of $>0.8$ and a minor allelic frequency of $>0.1$. PCR primers were designed with Primer 3 software (http://bioinfo.ut.ee/primer3-0.4.0/). The genetic information and the primers are shown in Table 2.

Following the manufacturer's protocol, we extracted genomic DNA from $200 \mu$ EDTA anticoagulated blood with a QIAamp DNA Blood Midi Kit (Qiagen, Hilden, Germany). A SNaPshot ${ }^{\circ}$ Kit was used to genotype the SNPs of the EREG gene.

We amplified all of the fragments by a Multiplex PCR reaction. The amplification system included $1 \times$ HotStar Taq buffer, $0.3 \mathrm{mM}$ dNTP, $3.0 \mathrm{mM} \mathrm{Mg}^{2+}, 1 \mathrm{U}$ HotStar Taq polymerase, $0.1 \mu \mathrm{M}$ primer and $1 \mu \mathrm{l}$ of DNA template. The reaction program carried out was as follows: 
Table 2 Single nucleotide polymorphisms (SNPS) of EREG gene

\begin{tabular}{|c|c|c|c|c|c|}
\hline$\overline{\mathrm{SNP}}$ & Gene & Chr & SNP property & PCR primer ${ }^{a}$ & Alleles \\
\hline \multirow[t]{2}{*}{ rs10518126 } & EREG & 4 & Intron1 & $\begin{array}{l}\text { F:CACAAGACTGCC } \\
\text { TTCCACCATAA }\end{array}$ & $\mathrm{C} / \mathrm{T}$ \\
\hline & & & & $\begin{array}{l}\text { R:CCTCTCAGGGCC } \\
\text { AATTTGAGGA }\end{array}$ & \\
\hline \multirow[t]{2}{*}{ rs2367707 } & EREG & 4 & exon4 & $\begin{array}{l}\text { F:TGGGTTATACTGG } \\
\text { TGTCCGATGTG }\end{array}$ & $A / G$ \\
\hline & & & & $\begin{array}{l}\text { R:AATATGTGGAAC } \\
\text { CGACGACTGTGA }\end{array}$ & \\
\hline \multirow[t]{2}{*}{ rs3806794 } & EREG & 4 & 5'-flanking & $\begin{array}{l}\text { F:CAGGGGAGCGA } \\
\text { CAGGATTAAGG }\end{array}$ & $\mathrm{A} / \mathrm{C}$ \\
\hline & & & & $\begin{array}{l}\text { R:TGAGACCCCTGC } \\
\text { TTCCAATGTG }\end{array}$ & \\
\hline \multirow[t]{2}{*}{ rs6446993 } & EREG & 4 & intron1 & $\begin{array}{l}\text { F:TGCACTCCATAG } \\
\text { CCTGTGATCG }\end{array}$ & $\mathrm{A} / \mathrm{T}$ \\
\hline & & & & $\begin{array}{l}\text { R:CCTCATTCCAACT } \\
\text { CCAGGGAGAA }\end{array}$ & \\
\hline \multirow[t]{2}{*}{ rs6836436 } & EREG & 4 & exon1 & $\begin{array}{l}\text { F:GTTCGCAGCACC } \\
\text { AGACAGTTGA }\end{array}$ & $\mathrm{G} / \mathrm{T}$ \\
\hline & & & & $\begin{array}{l}\text { R:GCACAGAGCATC } \\
\text { TCCATCCTCCT }\end{array}$ & \\
\hline
\end{tabular}

${ }^{a} F$ forward primer, $R$ reverse primer

$95^{\circ} \mathrm{C}$ for $2 \mathrm{~min}$; 11 cycles of $94^{\circ} \mathrm{C}$ for $20 \mathrm{~s}, 65^{\circ} \mathrm{C} \pm 0.5^{\circ} \mathrm{C}$ /cycle for $40 \mathrm{~s}$, and $72^{\circ} \mathrm{C}$ for $1 \mathrm{~min} 30 \mathrm{~s} ; 26$ cycles of $94^{\circ} \mathrm{C}$ for $20 \mathrm{~s}, 59^{\circ} \mathrm{C}$ for $30 \mathrm{~s}$, and $72^{\circ} \mathrm{C}$ for $1 \mathrm{~min} 30 \mathrm{~s}$; and finally $72{ }^{\circ} \mathrm{C}$ for $2 \mathrm{~min}$. Then, we added $5 \mathrm{U}$ of shrimp alkaline phosphataseand $2 \mathrm{U}$ of Exonuclease I to $15 \mu \mathrm{l}$ of PCR product for purification. Next, we incubated the mixture at $37^{\circ} \mathrm{C}$ for $60 \mathrm{~min}$ and then at $75^{\circ} \mathrm{C}$ for $15 \mathrm{~min}$. We performed the extension reaction with a SNaPshot ${ }^{\circ} \mathrm{Kit}$, and a SNaPshot genotyping system was optimized sufficiently and validated by sequencing. The extension primers used to detect polymorphisms in the EREG genes were rs2367707SF (TTTTTTTTCCGTCCACC AACCTTTAAGCAAAGA), rs10518126SR (TTTTTTT TTTTGGGCCACTTTATAGAATTTGGAAATA), rs68 36436SF (TTTTTTTTTTTTTTTTTTTTTTTTTTTT TTTCCCTTCTAGGCTGACAGCCGC), rs3806794SF (TTTTTTTTTTTTTTTTTTTTTTTAATAACAGGAA TTTTCTTCACAATGACT), and rs6446993SR (TTTT TTTTTTTTTTTTTTTTTTTTTTTTTTTTAACAGA AAGGCTATTTAGAAAA). The extension reaction mixture was as follows: $5 \mu \mathrm{l}$ of SNaPshot mix, $2 \mu \mathrm{l}$ of the extension primer mix, $2 \mu \mathrm{l}$ of purified PCR product and $2 \mu \mathrm{l}$ of ultrapure water. The extension procedure was as follows: $96^{\circ} \mathrm{C}$ for $1 \mathrm{~min}$ and 28 cycles of $96^{\circ} \mathrm{C}$ for $10 \mathrm{~s}, 52^{\circ} \mathrm{C}$ for $5 \mathrm{~s}$, and $60^{\circ} \mathrm{C}$ for $30 \mathrm{~s}$. Then, we added $1 \mathrm{U}$ of SAP to the extension products and incubated the mixture at $37^{\circ} \mathrm{C}$ for $60 \mathrm{~min}$ followed by $75^{\circ} \mathrm{C}$ for $15 \mathrm{~min}$ to purify the extension products. Then, we denatured the mixture using $1 \mu \mathrm{l}$ of purified extension product or $0.5 \mu \mathrm{l}$ of purified linkage product, $9 \mu \mathrm{l}$ of HiDi formamide and $0.5 \mu \mathrm{l}$ of the Liz120 size standard
(Applied Biosystems, Foster City, USA) at $95^{\circ} \mathrm{C}$ for 5 min. Finally, the mixture was loaded on an ABI 3730XL DNA Analyser (Applied Biosystems, Foster City, USA), and the results were analyzed using GeneMapper.

\section{Statistical analysis}

The EREG levels were represented as the mean \pm standard deviation, and the data between healthy controls and TB patients were analyzed with the t-test using SPSS 22.0. For each individual genotype, the OR and $95 \%$ confidence interval (CI) were estimated using logistic regression models adjusted for gender and age.

The Chi-squared test was used to evaluate whether the genotypic frequency in the population was consistent with the HWE. Data were confirmed to be within population equilibrium by calculating the HWE. We performed Chi-squared and Fisher's exact tests to compare allelic and genotypic frequencies. The haplotypes and linkage disequilibrium in the $\mathrm{HC}$ and TB patients were analyzed by the SHEsis system. After Bonferroni correction, $P^{*}$-values were five times the observed $P$-values, and $P$ values $<0.05$ were considered statistically significant.

\section{Results}

The EREG plasma levels from $\mathbf{3 0}$ healthy controls and $\mathbf{5 0}$ patients with tuberculosis

The plasma EREG levels (mean \pm SD) were 1014 \pm 733.9 $\mathrm{pg} / \mathrm{ml}$ in PTB group and $700.2 \pm 676.6 \mathrm{pg} / \mathrm{ml}$ in ЕРТВ group and were significantly different from those of the healthy control group (277 $\pm 105.4 \mathrm{pg} / \mathrm{ml})$ (Fig. 1).

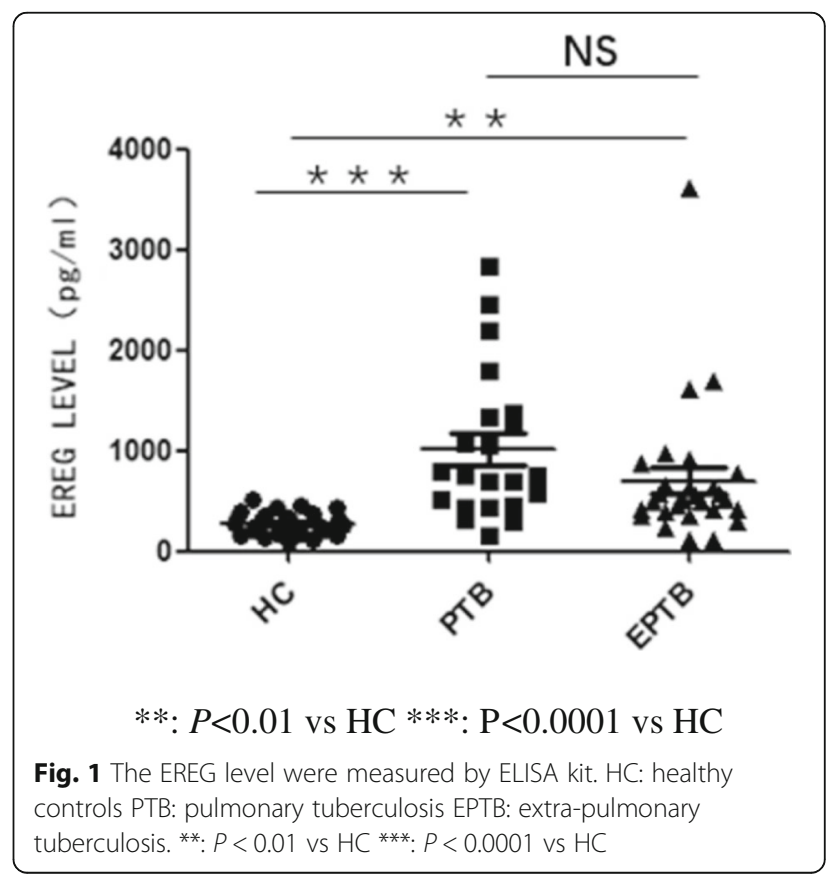


Data analyses of the EREG polymorphisms in PTB and HC patients

The allelic and genotypic frequencies of EREG polymorphisms in HC and PTB patients are shown in Table 3. We investigated the association of five EREG SNPs and PTB susceptibility using a case-control study. In the tested populations, all polymorphisms were consistent with Hardy-Weinberg equilibrium. Analyses of the distributions of PTB patients and healthy controls demonstrated that the EREG rs2367707 SNP contributed to susceptibility to PTB. The frequencies of the A allele of rs2367707 were significantly higher in $\mathrm{HC}$ than in PTB patients $(P=0.00019$, OR $(95 \% \mathrm{CI})=1.49(1.23-1.81))$.

Comparing the genotypic frequencies between healthy controls and PTB patients, we found that rs $2367707 \mathrm{~A} /$ $\mathrm{G}$ was more common in PTB patients $(P=0.00051)$. For the distribution of the other four EREG SNPs between

Table 3 Allele and genotypic frequencies of EREG SNPs in the PTB and controls

\begin{tabular}{|c|c|c|c|c|c|}
\hline$\overline{\mathrm{SNP}}$ & $\begin{array}{l}\text { Allele/ } \\
\text { genotype }\end{array}$ & PTB (\%) & $\mathrm{HC}(\%)$ & $P$ & OR[95\%Cl]a \\
\hline \multirow{5}{*}{ rs10518126 } & C & $774(91.3)$ & 1092 (91.0) & \multirow[t]{2}{*}{0.83} & \\
\hline & $\mathrm{T}$ & $74(8.7)$ & $108(9.0)$ & & \\
\hline & $\mathrm{C} / \mathrm{C}$ & $352(83.0)$ & $492(82.0)$ & \multirow[t]{3}{*}{0.20} & \\
\hline & $\mathrm{C} / \mathrm{T}$ & 70 (16.5) & $108(18.0)$ & & \\
\hline & $\mathrm{T} / \mathrm{T}$ & $2(0.5)$ & $0(0.0)$ & & \\
\hline \multirow[t]{5}{*}{ rs2367707 } & A & $292(34.4)$ & $312(26.0)$ & \multirow[t]{2}{*}{$0.00019^{*}$} & \multirow{2}{*}{$\begin{array}{l}1.49(1.23- \\
1.81)\end{array}$} \\
\hline & G & $556(65.6)$ & $888(74.0)$ & & \\
\hline & $\mathrm{A} / \mathrm{A}$ & $48(11.3)$ & $48(8.0)$ & \multirow[t]{3}{*}{$0.00051^{*}$} & \multirow{3}{*}{$\begin{array}{l}1.86(1.19- \\
2.88)\end{array}$} \\
\hline & $A / G$ & $196(46.2)$ & $216(36.0)$ & & \\
\hline & $\mathrm{G} / \mathrm{G}$ & $180(42.5)$ & $336(56.0)$ & & \\
\hline \multirow[t]{5}{*}{ rs3806794 } & A & $88(10.4)$ & $112(9.3)$ & \multirow[t]{2}{*}{0.43} & \\
\hline & C & 760 (89.6) & 1088 (90.7) & & \\
\hline & $\mathrm{A} / \mathrm{A}$ & $6(1.4)$ & $9(1.5)$ & \multirow[t]{3}{*}{0.63} & \\
\hline & $\mathrm{A} / \mathrm{C}$ & 76 (17.9) & $94(15.7)$ & & \\
\hline & $\mathrm{C} / \mathrm{C}$ & $342(80.7)$ & 497 (82.8) & & \\
\hline \multirow[t]{5}{*}{ rs6446993 } & A & 364 (42.9) & $486(40.5)$ & \multirow[t]{2}{*}{0.27} & \\
\hline & $\mathrm{T}$ & $484(57.1)$ & $714(59.5)$ & & \\
\hline & $\mathrm{A} / \mathrm{A}$ & 76 (17.9) & $108(18.0)$ & \multirow[t]{3}{*}{0.22} & \\
\hline & $\mathrm{A} / \mathrm{T}$ & $212(50.0)$ & $270(45.0)$ & & \\
\hline & $\mathrm{T} / \mathrm{T}$ & $136(32.1)$ & $222(37.0)$ & & \\
\hline \multirow[t]{5}{*}{ rs6836436 } & G & $76(9.0)$ & $126(10.5)$ & \multirow[t]{2}{*}{0.25} & \\
\hline & $\mathrm{T}$ & 772 (91.0) & 1074 (89.5) & & \\
\hline & $\mathrm{G} / \mathrm{G}$ & $2(0.5)$ & $6(1.0)$ & \multirow[t]{3}{*}{0.44} & \\
\hline & $\mathrm{G} / \mathrm{T}$ & $72(17.0)$ & $114(19.0)$ & & \\
\hline & $\mathrm{T} / \mathrm{T}$ & $350(82.5)$ & $480(80.0)$ & & \\
\hline
\end{tabular}

\footnotetext{
* $P$ indicates a significant association after Bonferroni correction for multiple testing at significance level $a=0.05$

${ }^{a}$ Adjusted for age and gender from a logistics regression model
}

PTB patients and controls, no significant differences were observed.

\section{Data analyses of the EREG polymorphisms in EPTB patients and $\mathrm{HC}$}

The allelic and genotypic frequencies of EREG polymorphism in EPTB patients and healthy controls are indicated in Table 4. Analyses of the distributions of EPTB patients and healthy controls demonstrated that the EREG rs2367707 and rs6446993 SNPs contributed to susceptibility to EPTB. The frequencies of the A allele of rs2367707 and the $\mathrm{T}$ allele of rs6446993 were significantly higher in healthy controls than in ЕРТВ patients $(P=0.00029$, OR $(95 \% \mathrm{CI})=1.64(1.28-2.08)$; $P=0.00087$, OR $(95 \% \mathrm{CI})=1.54(1.23-1.94))$.

Comparing genotypic frequencies between healthy controls and EPTB patients, we found that rs2367707 A/G

Table 4 Allele and genotypic frequencies of EREG SNPs in the EPTB and controls

\begin{tabular}{|c|c|c|c|c|c|}
\hline$\overline{\mathrm{SNP}}$ & $\begin{array}{l}\text { Allele/ } \\
\text { genotype }\end{array}$ & EPTB (\%) & $\mathrm{HC}(\%)$ & $P$ & OR $[95 \% \mathrm{Cl}]^{\mathrm{a}}$ \\
\hline \multirow[t]{5}{*}{ rs10518126 } & C & 353 (88.2) & 1092 (91.0) & 0.11 & \\
\hline & $\mathrm{T}$ & $47(11.7)$ & $108(9.0)$ & & \\
\hline & $\mathrm{C} / \mathrm{C}$ & $158(79.0)$ & $492(82.0)$ & $0.0026^{*}$ & $1.08(0.71-1.64)$ \\
\hline & $\mathrm{C} / \mathrm{T}$ & 37 (18.5) & $108(18.0)$ & & \\
\hline & $\mathrm{T} / \mathrm{T}$ & $5(2.5)$ & $0(0.0)$ & & \\
\hline \multirow[t]{5}{*}{ rs2367707 } & $A$ & $146(36.5)$ & $312(26.0)$ & $0.00029^{*}$ & $1.64(1.29-2.08)$ \\
\hline & G & $254(63.5)$ & $888(74.0)$ & & \\
\hline & $\mathrm{A} / \mathrm{A}$ & $25(12.5)$ & $48(8.0)$ & $0.0012^{*}$ & $2.22(1.29-3.83)$ \\
\hline & $A / G$ & $96(48.0)$ & $216(36.0)$ & & \\
\hline & $\mathrm{G} / \mathrm{G}$ & 79 (39.5) & $336(56.0)$ & & \\
\hline \multirow[t]{5}{*}{ rs3806794 } & A & $46(11.5)$ & $112(9.3)$ & 0.21 & \\
\hline & C & 354 (88.5) & 1088 (90.7) & & \\
\hline & $\mathrm{A} / \mathrm{A}$ & $7(3.5)$ & $9(1.5)$ & 0.21 & \\
\hline & $\mathrm{A} / \mathrm{C}$ & $32(16.0)$ & $94(15.7)$ & & \\
\hline & $\mathrm{C} / \mathrm{C}$ & $161(80.5)$ & 497 (82.8) & & \\
\hline \multirow[t]{5}{*}{ rs6446993 } & $A$ & 205 (51.2) & $486(40.5)$ & $0.00087^{*}$ & $1.54(1.23-1.94)$ \\
\hline & $\mathrm{T}$ & 195 (48.7) & $714(59.5)$ & & \\
\hline & $\mathrm{A} / \mathrm{A}$ & $55(27.5)$ & $108(18.0)$ & $0.0069^{*}$ & $0.68(0.45-1.02)$ \\
\hline & $\mathrm{A} / \mathrm{T}$ & $95(47.5)$ & $270(45.0)$ & & \\
\hline & $\mathrm{T} / \mathrm{T}$ & $50(25.0)$ & $222(37.0)$ & & \\
\hline \multirow[t]{5}{*}{ rs6836436 } & G & $50(12.5)$ & $126(10.5)$ & 0.27 & \\
\hline & $\mathrm{T}$ & $350(87.5)$ & 1074 (89.5) & & \\
\hline & $\mathrm{G} / \mathrm{G}$ & $5(2.5)$ & $6(1.0)$ & 0.27 & \\
\hline & $\mathrm{G} / \mathrm{T}$ & $40(20.0)$ & $114(19.0)$ & & \\
\hline & $\mathrm{T} / \mathrm{T}$ & $155(77.5)$ & $480(80.0)$ & & \\
\hline
\end{tabular}

* $P$ indicates a significant association after Bonferroni correction for multiple testing at significance level $\mathrm{a}=0.05$

${ }^{a}$ Adjusted for age and gender from a logistics regression model 
Table 5 Estimated frequencies of haplotypes consisting of EREG SNPs in PTB and controls

\begin{tabular}{llllll}
\hline Haplotype & PTB (\%) & Control (\%) & X2 & $P$ & OR[95\%Cl] \\
\hline CACAT & $279.88(33.0)$ & $303.06(25.3)$ & 13.02 & 0.00031 & $1.43(1.18-1.74)$ \\
CGATT & $84.46(10.0)$ & $104.24(8.7)$ & 0.75 & 0.39 & $1.14(0.85-1.54)$ \\
CGCTT & $387.42(45.7)$ & $607.71(50.6)$ & 6.77 & 0.0093 & $0.79(0.66-0.94)$ \\
TGCAG & $73.76(8.7)$ & $101.12(8.5)$ & 0.011 & 0.92 & $\begin{array}{l}1.017(0.74- \\
\text { (1.39) }\end{array}$
\end{tabular}

${ }^{a}$ Frequencies $<0.03$ were excluded from the analysis

Global $\mathrm{p}<0.01$

The order of the SNPs in the haplotype is rs10518126 rs2367707 rs3806794 rs6446993 rs6836436

and rs6446993 A/T were more common in EPTB patients $(P=0.0012, P=0.0069)$.

\section{Haplotype and linkage disequilibrium (LD) analyses}

The haplotype data between the two disease forms are shown in Table 5 and Table 6. We identified 11 haplotypes with SHEsis, and seven were excluded with a frequency $<0.03$. Haplotype analysis showed that the EREG CACAT and CGCTT haplotypes were significantly related to PTB and EPTB and that the CACAT haplotype was a significantly "beneficial" haplotype $(P=0.00031$ for PTB, $P=0.000053$ for EPTB); the other two haplotypes showed no significant association.

We assessed the LD among SNPs with both D' and $r^{2}$. The LD structure constructed with five SNPs (rs10518126, rs237707, rs3806794, rs6446993, and rs6836436) is shown in Fig. 2. The degree of LD among the five SNPs was relatively high.

\section{Discussion}

Tuberculosis is an infectious disease that can invade multiple systems, such as the pulmonary, intestinal, renal and central nervous systems (CNS). Numerous immune signaling pathways, inflammation responses and cell types (e.g., macrophage, dendritic cells, T cells) are involved in the initiation, progression and pathogenesis of tuberculosis. Macrophages express Toll-like receptors (TLRs), which can recognize pathogen-associated

Table 6 Estimated frequencies of haplotypes consisting of EREG SNPs in EPTB and controls

\begin{tabular}{llllll}
\hline Haplotype & EPTB (\%) & $\begin{array}{l}\text { Control } \\
(\%)^{\mathrm{a}}\end{array}$ & X2 & P & OR[95\%Cl] \\
\hline CACAT & $145.99(36.5)$ & $303.06(25.3)$ & 16.35 & 0.000053 & $1.65(1.29-2.10)$ \\
CGATT & $45.99(11.5)$ & $104.24(8.7)$ & 2.29 & 0.13 & $1.33(0.92-1.92)$ \\
CGCTT & $149.01(37.3)$ & $607.71(50.6)$ & 26.09 & $3.32 \times 10^{-7}$ & $0.55(0.43-0.69)$ \\
TGCAG & $47.00(11.7)$ & $101.12(8.4)$ & 3.35 & 0.070 & $1.41(0.98-2.03)$
\end{tabular}

${ }^{a}$ Frequencies $<0.03$ were excluded from the analysis

Global $\mathrm{p}<0.01$

The order of the SNPs in the haplotype is rs10518126 rs2367707 rs3806794 rs6446993 rs6836436 molecular patterns (PAMPs) of $M t b$ and regulate the production of immune-associated cytokines [11]. EREG acts as an epidermal growth factor receptor ligand that exhibits a regulatory property by inhibiting the growth of epithelial cells [12] as well as regulating inflammation [13] and the immune response [10] during infection. NTT Thuong [8] showed that the expression of EREG depends on TLR activation, may regulate TLR-associated signaling of macrophages and is a highly induced TLR-dependent gene associated with risk for TB. Many studies showed that EREG may impact bacterial pathogenesis and disease outcome through a biosynthesis and regulatory role in innate immune defenses. Previous studies have demonstrated that EREG played a potential role in various bacterial infections, such as Mycoplasma pneumonia [14], Streptococcus suis [15] and Mycobacterium tuberculosis [7], but because of the different interactions between the bacterial and the host immune response, the phenotypic effects on different infections were also different.

Associations of polymorphisms in EREG and susceptibility to TB have been reported in a variety of populations. In populations from Guinea-Bissau and Gambia, the EREG SNP rs1563826 was almost significant [16]. Another case-control study showed evidence for an association between rs7675690 in EREG and pulmonary TB, particularly meningeal tuberculosis [8]. In our study, we assessed EREG plasma levels, and we analyzed a Chinese population ( $n=600$ controls and $n=624$ cases) for polymorphisms in EREG and whether previously described associations with TB in other populations would be replicated in a Chinese population. We evaluated five SNPs of EREG for associations with TB and different clinical forms. Our hypothesis was that SNPs of EREG would confer susceptibility to TB.

Our data showed significantly higher plasma concentrations of EREG in TB patients compared to the healthy controls. EREG has been shown to be upregulated on macrophages in TB; this finding was consistent with our results. Moreover, we found an association of an EREG polymorphism with TB. The allelic and genotypic frequencies of the EREG gene differed between the two groups. The $\mathrm{G}$ allele of rs2367707 was more universal in the controls than in PTB and EPTB patients. Moreover, the rs2367707 A/G genotype showed a high risk of association with TB. In our study, the distribution of haplotypes between controls and patients was significantly different, particularly for CACAT and CGCTT. EREG SNPs within PTB and EPTB were further examined. The A allele and A/G genotype of rs2367707 showed significant effects on PTB. The alleles and genotypes of the EREG SNPs rs2367707 and rs6446993 were strongly associated with EPTB. A candidate gene study found that the EREG rs2367707 was a potential genetic risk factor 

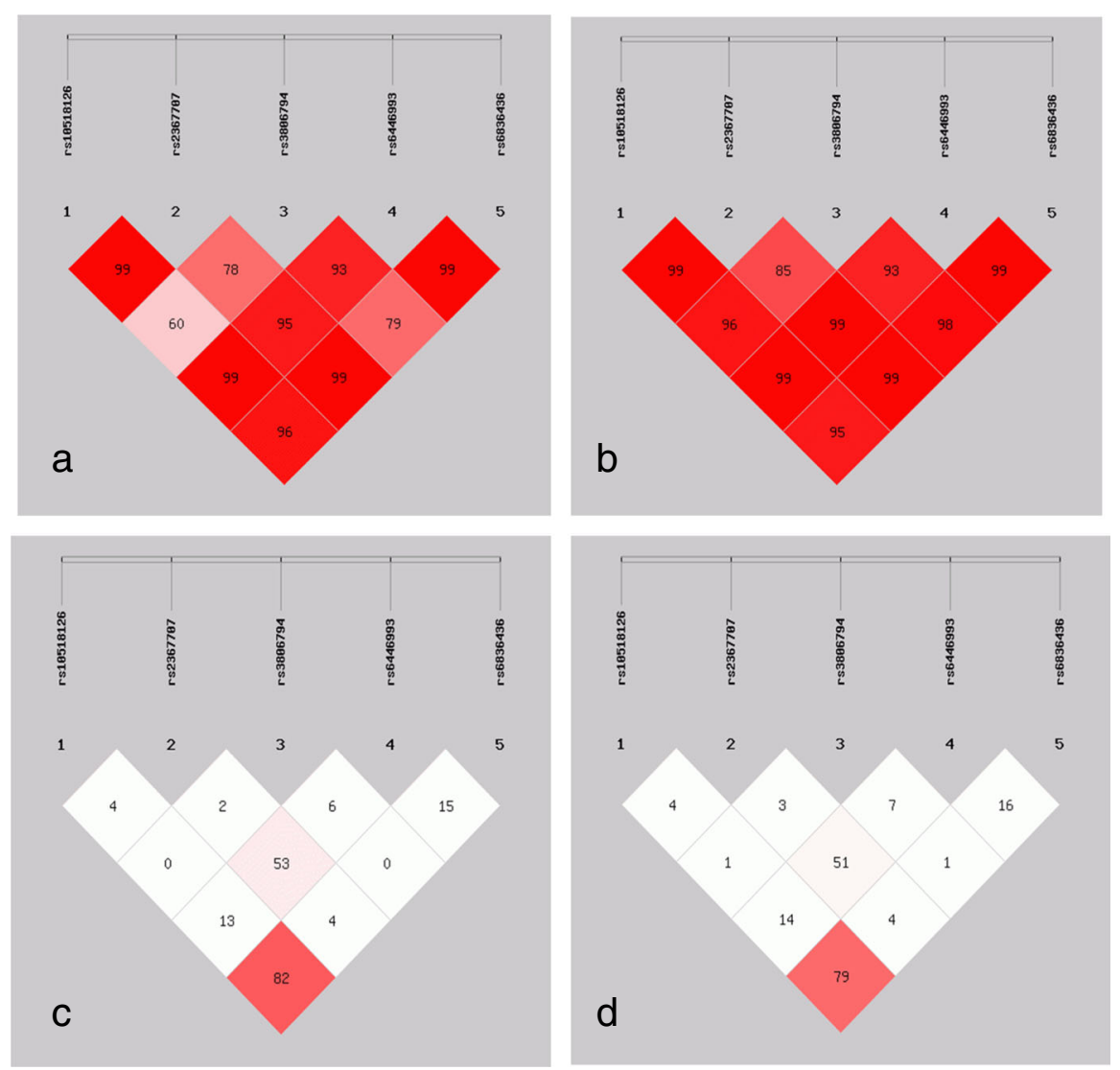

\section{D' values: a: PTB vs Controls, b: EPTB vs Controls \\ $\mathrm{R}^{2}$ values: c:PTB vs Controls.d:EPTB vs Controls}

Fig. 2 Linkage disequilibrium (LD) structure of SNPs in EREG. D' values (\%) and $r^{2}$ are indicated on squares. Pairwise values are color coded: high values are dark, low values are light. All values were generated using SHEsis software. D' values: a PTB vs Controls, $\mathbf{b}$ EPTB vs Controls. R²values: c PTB vs Controls. d EPTB vs Controls

for chronic temporomandibular disorders (TMD) [17], but the mechanism was unknown. These data showed that rs2367707 in exon4 of EREG was related to disease, and further investigations should concentrate on its function in disease. In addition, we showed that rs6446993 located in the intron may affect the activity of EREG because SNPs located in introns may influence RNA splicing by altering the formation of splicesomes, leading to changes in protein structure and folding. Thus, it is a novel target for therapy.

EREG has been identified as a regulator of inflammation and is associated with disease; its levels are higher in patients with chronic inflammatory disorders [18]. Previous studies have shown that EREG expression is induced in human macrophages and monocytes after Mtb stimulation [19]. EREG is expressed not only in macrophages but also in keratinocytes, and a previous study revealed that EREG-deficient mice develop chronic dermatitis, a major cause of skin inflammation [20]. In recent years, many researchers have demonstrated the effect of EREG in controlling inflammation on colon disease [21], rhinosinusitis [22] and cancer [23]. Several previous experiments have concentrated on the association between EREG SNPs and various diseases. Takeru Wakatsukiet al. [24] identified SNPs within the genomic regions of EREG in gastric cancer for the first time and demonstrated an association of those SNPs with the 3-year RFS (recurrence free) and 3 -year overall survival rates. In a study of Behçet's disease (BD) with a case-control study of 976 Iranian patients and 839 healthy controls, a new SNP, rs6845297, located downstream of EREG, was associated with BD [25].

In conclusion, our paper suggests genetic variants of EREG confer susceptibility to TB. We demonstrated that EREG polymorphisms may affect the development of $\mathrm{TB}$, which suggests that EREG may be a potential target for TB treatment. However, these results should be conducted with larger numbers of subjects and subjects from other geographic locations. Moreover, experimental 
research of how the EREG polymorphism affects the molecular mechanism of the occurrence and development of TB is needed.

\section{Conclusions}

In summary, we suggest that EREG gene polymorphism confers susceptibility to pulmonary tuberculosis and extra-pulmonary tuberculosis. However, these results should be conducted with larger and geographically broader population samples. Moreover, experimental research on the molecular mechanism of how the EREG polymorphism affects the occurrence and development of $\mathrm{TB}$ is needed.

\section{Abbreviations}

EPTB: Extrapulmonary tuberculosis; EREG: Epiregulin; LD: Linkage

disequilibrium; Mtb: Mycobacterium tuberculosis; PTB: Pulmonary tuberculosis; SNP: Single nucleotide polymorphism; TLRs: Toll-like receptors

\section{Acknowledgements}

Special thanks to Baoshan Wan from Shanghai Pulmonary Hospital Affiliated to Tongji University School of Medicine, Shanghai, P.R.China for his assistance in editing the English language in the revised manuscript.

\section{Funding}

This work was supported by the National Great Research Program of China (2018zx 10103001-004) and the National Natural Science Foundation of China (81371775).

\section{Availability of data and materials}

The datasets used and analyzed during the current study are available from the corresponding author upon reasonable request.

\section{Authors' contributions}

WC, LLL and JY conceived and designed the experiments. YLZ selected the tagSNPS, WC, WWC and RRZ collected the blood samples and extracted DNA from the blood samples. WC and LLL wrote the manuscript. WWC contributed to the interpretation of the results and revised the manuscript. $\mathrm{LL}$ and $\mathrm{JC}$ participate in revising the manuscript. All authors read and approved the final manuscript.

\section{Ethics approval and consent to participate}

All subjects were willing to participate in the study and signed informed consent forms. In addition, the Ethics Committee of Shanghai Pulmonary Hospital affiliated with Tongji University School of Medicine approved the study. The ethics approval reference number was K17-056.

\section{Consent for publication}

Not applicable.

\section{Competing interests}

The authors declare that they have no competing interests.

\section{Publisher's Note}

Springer Nature remains neutral with regard to jurisdictional claims in published maps and institutional affiliations.

\section{Author details}

${ }^{1}$ Shanghai Key Laboratory of Mycobacterium Tuberculosis, Shanghai Pulmonary Hospital Affiliated to Tongji University School of Medicine, Shanghai, People's Republic of China. ${ }^{2}$ National Center for Tuberculosis Control and Prevention, Chinese Center for Disease Control and Prevention, Beijing, People's Republic of China.
Received: 1 June 2018 Accepted: 28 November 2018

Published online: 11 January 2019

\section{References}

1. World Health Organization. Global tuberculosis report 2017[J]. 2017.

2. Awuh JA, Flo TH. Author Correction: Molecular basis of mycobacterial survival in macrophages. Cell Mol Life Sci. 2018;75(1):161. https://doi.org/10. 1007/s00018-017-2683-x [published Online First: Epub Date].

3. Van Tong $H$, Velavan TP, Thye $T$, et al. Human genetic factors in tuberculosis: an update. Trop Med Int Health. 2017;22(9):1063-71. https:// doi.org/10.1111/tmi.12923 [published Online First: Epub Date].

4. Thuong NT, Hawn TR, Thwaites GE, et al. A polymorphism in human TLR2 is associated with increased susceptibility to tuberculous meningitis. Genes Immunity. 2007;8(5):422-8. https://doi.org/10.1038/sj.gene.6364405 [published Online First: Epub Date].

5. Strachan L, Murison JG, Prestidge RL, et al. Cloning and biological activity of epigen, a novel member of the epidermal growth factor superfamily. J Biol Chem. 2001;276(21):18265-71. https://doi.org/10.1074/jbc.M006935200 [published Online First: Epub Date].

6. Thuong NT. Host Genetic susceptibility to Tuberculous meningitis in Vietnam. UK: PhD. Open University; 2008.

7. Nalbandian A, Yan BS, Pichugin A, et al. Lung carcinogenesis induced by chronic tuberculosis infection: the experimental model and genetic control. Oncogene. 2009;28(17):1928-38. https://doi.org/10.1038/onc.2009.32 [published Online First: Epub Date].

8. Thuong NT, Hawn TR, Chau TT, et al. Epiregulin (EREG) variation is associated with susceptibility to tuberculosis. Genes Immun. 2012;13(3):27581. https://doi.org/10.1038/gene.2011.83 [published Online First: Epub Date].

9. Sugiyama S, Nakabayashi K, Baba I, et al. Role of epiregulin in peptidoglycan-induced proinflammatory cytokine production by antigen presenting cells. Biochem Biophys Res Commun. 2005;337(1):271-4. https:// doi.org/10.1016/j.bbrc.2005.09.050 [published Online First: Epub Date].

10. Shirasawa S, Sugiyama S, Baba I, et al. Dermatitis due to epiregulin deficiency and a critical role of epiregulin in immune-related responses of keratinocyte and macrophage. Proceedings of the National Academy of Sciences of the United States of America. 2004;101(38):13921-6. https://doi. org/10.1073/pnas.0404217101 [published Online First: Epub Date].

11. Xu G, Wang J, Gao GF, et al. Insights into battles between Mycobacterium tuberculosis and macrophages. Protein Cell. 2014;5(10):728-36. https://doi. org/10.1007/s13238-014-0077-5 [published Online First: Epub Date].

12. Shirakata $Y$, Komurasaki T, Toyoda $H$, et al. Epiregulin, a novel member of the epidermal growth factor family, is an autocrine growth factor in normal human keratinocytes. J Biol Chem. 2000;275(8):5748-53.

13. Harada M, Kamimura D, Arima $Y$, et al. Temporal expression of growth factors triggered by epiregulin regulates inflammation development. J Immunol. 2015;194(3):1039-46. https://doi.org/10.4049/jimmunol.1400562 [published Online First: Epub Date].

14. Arae K, Hirata M, Kurata S, et al. Mycoplasma pneumoniae induces interleukin-8 production via the epidermal growth factor receptor pathway. Microbiol Immunol. 2011;55(10):748-50. https://doi.org/10.1111/j.1348-0421. 2011.00375.x [published Online First: Epub Date]

15. Yang XP, Fu JY, Yang RC, et al. EGFR transactivation contributes to neuroinflammation in Streptococcus suis meningitis. J Neuroinflamm. 2016; 13(1):274. https://doi.org/10.1186/s12974-016-0734-0 [published Online First: Epub Date]

16. White MJ, Tacconelli A, Chen JS, et al. Epiregulin (EREG) and human VATPase (TCIRG1): genetic variation, ethnicity and pulmonary tuberculosis susceptibility in Guinea-Bissau and The Gambia. Genes and immunity. 2014; 15(6):370-7. https://doi.org/10.1038/gene.2014.28 [published Online First: Epub Date].

17. Smith SB, Maixner DW, Greenspan JD, et al. Potential genetic risk factors for chronic TMD: genetic associations from the OPPERA case control study. J Pain. 2011;12(11 Suppl):T92-101. https://doi.org/10.1016/j.jpain.2011.08.005 [published Online First: Epub Date].

18. Ogura $\mathrm{H}$, Atsumi $\mathrm{T}$, Bando $\mathrm{H}$, et al. The reverse-direction method links mass experimental data to human diseases. Archivumimmunol Therapiaeexperim. 2014;62(1):41-5. https://doi.org/10.1007/s00005-013-0255-9 [published Online First: Epub Date].

19. Thuong NT, Dunstan SJ, Chau TT, et al. Identification of tuberculosis susceptibility genes with human macrophage gene expression profiles. 
PLoS Pathogens. 2008;4(12):e1000229. https://doi.org/10.1371/journal.ppat. 1000229 [published Online First: Epub Date].

20. Pastore S, Mascia F, Mariani V, et al. The epidermal growth factor receptor system in skin repair and inflammation. J Invest Dermatol. 2008;128(6):136574. https://doi.org/10.1038/sj.jid.5701184 [published Online First: Epub Date].

21. Nishimura $\mathrm{T}$, Andoh $\mathrm{A}$, Inatomi $\mathrm{O}$, et al. Amphiregulin and epiregulin expression in neoplastic and inflammatory lesions in the colon. Oncol Rep. 2008;19(1):105-10.

22. Homma T, Kato A, Sakashita M, et al. Potential Involvement of the Epidermal Growth Factor Receptor Ligand Epiregulin and Matrix Metalloproteinase-1 in Pathogenesis of Chronic Rhinosinusitis. Am J Respir Cell Mol Biol. 2017; 57(3):334-45. https://doi.org/10.1165/rcmb.2016-03250C [published Online First: Epub Date].

23. Dapito DH, Mencin A, Gwak GY, et al. Promotion of hepatocellular carcinoma by the intestinal microbiota and TLR4. Cancer Cell. 2012;21(4): 504-16. https://doi.org/10.1016/j.ccr.2012.02.007 [published Online First: Epub Date].

24. Wakatsuki T, Stintzing S, Zhang W, et al. Single nucleotide polymorphisms in AREG and EREG are prognostic biomarkers in locally advanced gastric cancer patients after surgery with curative intent. Pharmacogenet Genomics. 2014;24(11):539-47. https://doi.org/10.1097/FPC. 0000000000000087 [published Online First: Epub Date]

25. Xavier JM, Krug T, Davatchi F, et al. Gene expression profiling and association studies implicate the neuregulin signaling pathway in Behcet's disease susceptibility. J Mol Med. 2013;91(8):1013-23. https://doi.org/10. 1007/s00109-013-1022-4 [published Online First: Epub Date].

Ready to submit your research? Choose BMC and benefit from:

- fast, convenient online submission

- thorough peer review by experienced researchers in your field

- rapid publication on acceptance

- support for research data, including large and complex data types

- gold Open Access which fosters wider collaboration and increased citations

- maximum visibility for your research: over $100 \mathrm{M}$ website views per year

At $\mathrm{BMC}$, research is always in progress.

Learn more biomedcentral.com/submissions 